\title{
Genetic Characterization of Rainfed Durum Wheat Genotypes Based On Functional Markers Associated With Grain Quality Proteins
}

Zahra Moradi Kheibary ( $\square$ zahra.moradi64@yahoo.com)

Islamic Azad University Science and Research Branch https://orcid.org/0000-0001-7879-7855

Reza Azizinezhad

Islamic Azad University Science and Research Branch

Ali Mehras Mehrabi

Islamic Azad University Science and Research Branch

Mahmood Khosrowshahli

Islamic Azad University Science and Research Branch

Alireza Etminan

Islamic Azad University Kermanshah Branch Young Researchers Club

\section{Research Article}

Keywords: Durum wheat, Functional marker, Genetic variability, HMWGs, LMWGs

Posted Date: August 4th, 2021

DOI: https://doi.org/10.21203/rs.3.rs-675853/v1

License: (c) (7) This work is licensed under a Creative Commons Attribution 4.0 International License. Read Full License 


\begin{abstract}
Analysis of genetic diversity provides helpful information necessary to develop the breeding and conservation strategies of crops. In this study, the genetic diversity and population structure of 90 durum wheat genotypes maintained at Sararud Dryland Agricultural Research Institute, Kermanshah, Iran, were evaluated by using 23 gene-specific markers (functional markers, FMs) encoding high and low molecular weight glutenin and gliadin alleles. Results showed that 12 out of the $23 \mathrm{FMs}$ used were polymorphic and amplified 52 polymorphic loci. Primer $A \times 2^{*}$ had the highest discriminatory power. The population structure analysis classified the durum wheat collection into four populations. On average, population 4 , consisting of 8 genotypes, had the highest allele number as well as genetic variation. Analysis of molecular variance indicated that $82 \%$ of the total variation was distributed among populations. The diversity among populations and gene flow were 0.14 and 3.03, respectively. The Jaccard distance coefficient revealed that genetic dissimilarities ranged from 0.031 between $\mathrm{G} 62$ and $\mathrm{G} 65$ to 0.725 between G36 and G51. Neighbor-joining method clustered individuals into six main groups. Results showed a remarkable level of genetic diversity among studied durum wheat genotypes which can be of interest for future breeding programs.
\end{abstract}

\title{
Introduction
}

Durum wheat (Triticum turgidum L. subsp. durum, $2 n=4 x=28 ; A A B B$ ) is the only tetraploid species of commercial wheat cultivated over almost 17 million ha of the Mediterranean basin and other semi-arid areas globally, with 38.1 million t (Aslan-parviz et al. 2020; Etminan et al. 2018; Xynias et al. 2020). This plant is the primary source of semolina, often used in food products such as pasta, couscous, bulgur, various bread, and other local products (El Haddad et al. 2021; Magallanes-López et al. 2017).

Genetic variation is an essential component of plant genetics, breeding, conservation, and evolution programs that provides a basis for selecting superior parent compounds and predicting offspring performance (Fattah and Tayib 2020). The study of genetic variation leads to discovering new alleles or genes in the population under investigation and thus maximizes the efficiency of breeding programs (Alemu et al. 2020). So far, numerous breeding programs have been designed and implemented to study and measure genetic variation in durum wheat germplasm (Aslan-parviz et al. 2020). Molecular markers are among the tools that have been successfully used to dissect many plant populations' genetic architecture and structure (Fayaz et al. 2019). During the past decades, the use of molecular markers at the gene level, such as SSR, RFLP, RAPD, AFLP, DArT, etc., has become common in wheat genetic analysis (Kumar et al. 2021). However, these markers are neutral, which can be somewhat distant from the genes, and are often relevant to a particular population or parents (Kage et al. 2016). Another class of DNA molecular markers is called gene-specific or functional molecular markers (FMs), based on polymorphisms within genes and are therefore directly related to the desired trait allele. Hence, it has been suggested that FMs are preferable to random markers, especially in marker-assisted selection projects (Li et al. 2020).

After yield, quality is one of the most critical aspects of wheat breeding programs. The quality of wheat-based food products is determined by the grain quality characteristics (Magallanes-López et al. 2017), including high protein content, high gluten strength, and the tenacity, strength, and extensibility of dough (Regina and Guzmán 2020). The genetic control of these properties depends mainly on the structure of glutenin and gliadin proteins. Glutenins are divided into two subunits of High Molecular Weight (HMWGs) and Low Molecular Weight subunits (LMWGs). In durum wheat, HMWGs are encoded by G/u-A1 and G/u-B1 loci on the long arms of the group-1 homoeologous chromosomes, whereas LMWGs are encoded by G/u-A3, G/uB3, and G/u-B2 genes on the short arms of group-1 homoeologous chromosomes (Chegdali et al. 2020). The majority of $y$-gliadin and $\omega$-gliadin genes are encoded by the Gli-1 loci on the short arm of chromosome 1, whereas the a-gliadins encoded on the group-6 chromosomes (Hsia and Anderson 2001).

In Iran, the production and consumption of pasta are widespread. However, due to a shortage of durum semolina, bread wheat flour is often used in pasta production resulting in technological difficulties and reduced quality (Irani 2000). Therefore, several projects were started to select suitable and high-quality durum wheat genotypes. Due to different alleles, it seems possible to study genetic diversity based on specific markers related to grain proteins responsible for quality. In this regard, this research aimed to investigate the genetic variation and population structure of a set of durum wheat genotypes using functional markers associated with grain quality proteins.

\section{Materials And Methods Plant materials and DNA extraction}

In this study, 90 durum wheat genotypes provided by Sararud Rainfed Research Center, Kermanshah, Iran, were used (Table 1). All genotypes were rainfed and showed good performance in various experiments. Molecular experiments and genotyping of samples were performed at the Islamic Azad University of Kermanshah. For this purpose, three seeds of each genotype were planted in the greenhouse, and the genomic DNA was extracted by the CTAB method from plant leaves at the five-leaf stage (Murray and Thompson 1980). The DNA quality of the samples was then examined using $1 \%$ agarose gel. 


\begin{tabular}{|c|c|}
\hline Genotype & Pedigree \\
\hline G1 & MÂALI/10/ALTAR 84/CMH82A.1062//ALTAR 84/3/YAZI_10/4/SNITAN/9/USDA595/3/D67.3/RABI//CRA/4/ALO/5/HUI/YAV_1/6/ARDENTE/7/ト \\
\hline G2 & MOHAWK/4/DUKEM_1//PATKA_7/YAZI_1/3/PATKA_7/YAZI_1/6/PLATA_6/GREEN_17/3/CHEN/AUK//BISU*2/5/PLATA_3//CREX/ALLA/3/SOM \\
\hline G3 & GUAYACAN INIA/2*SNITAN/3/SOMAT_3/GREEN_22//2*RASCON_37/2*TARRO_2 \\
\hline G4 & ALTAR 84/STINT//SILVER_45/3/GUANAY/4/GREEN_14//YAV_10/AUK/5/SOMAT_4/INTER_8/6/SOMAT_3/GREEN_22//2*RASCON_37/2*TARRC \\
\hline G5 & PLATA_7/ILBOR_1//SOMAT_3/3/CABECA_2/PATKA_4//BEHRANG/10/1A.1D 5 + 1-06/2*WB881//1A.1D 5+1-06/3*MOJO/3/SO0TY_9/RASCI \\
\hline G6 & $\begin{array}{l}\text { CBC } 509 \text { CHILE/6/ECO/CMH76A.722//BIT/3/ALTAR } \\
\text { 84/4/AJAIA_2/5/KJOVE_1/7/AJAIA_12/F3LOCAL(SEL.ETHIO.135.85)//PLATA_13/8/SOOTY_9/RASCON_37//WODUCK/CHAM_3/9/SOOTY_9/F } \\
\text { 12Y-1M-06Y-0B }\end{array}$ \\
\hline G7 & $\begin{array}{l}\text { CBC } 509 \text { CHILE/6/ECO/CMH76A.722//BIT/3/ALTAR } \\
\text { 84/4/AJAIA_2/5/KJOVE_1/7/AJAIA_12/F3LOCAL(SEL.ETHI0.135.85)//PLATA_13/8/SOOTY_9/RASCON_37//WODUCK/CHAM_3/9/SOOTY_9/F } \\
\text { 18Y-1M-06Y-0B }\end{array}$ \\
\hline G8 & $\begin{array}{l}\text { GUAYACAN INIA/GUANAY//PORRON_4/BEJAH_7/7/CAMAYO//HYDRANASSA30/SILVER_5/3/SOOTY_9/RASCON_37/5/DUKEM_15/3/BISU_1/F } \\
\text { 84/ALD/4/POD_11/YAZI_1/5/VANRRI }\end{array}$ \\
\hline G9 & CND0/VEE//PLATA_8/3/6*PLATA_11/6/PLATA_8/4/GARZA/AFN//CRA/3/GTA/5/RASCON/9/USDA595/3/D67.3/RABI//CRA/4/ALO/5/HUI/YAI \\
\hline G10 & $\begin{array}{l}\text { RANCO//CIT71/CII/3/COMDK/4/TCHO//SHWA/MALD/3/CREX/5/SNITAN/6/YAZI_1/AKAKI_4//SOMAT_3/3/AUK/GUIL//GREEN/9/CBC 509 CH } \\
\text { 84/4/AJAIA_2/5/KJOVE_1/7/AJAIA_12/F3LOCAL(SEL.ETHI0.135.85)//PLATA_13/8/SOOTY_9/RASCON_37//WODUCK/CHA }\end{array}$ \\
\hline G11 & CIRNO C 2008 \\
\hline G12 & CBC 509 CHILE/5/2*AJAIA_16//HORA/JRO/3/GAN/4/ZAR/6/AJAIA_12/F3LOCAL(SEL.ETHIO.135.85)//PLATA_13/4/CHEN_1/TEZ/3/GUIL//CIT \\
\hline G13 & $\begin{array}{l}\text { CBC } 509 \text { CHILE/6/ECO/CMH76A.722//BIT/3/ALTAR 84/4/AJAIA_2/5/KJOVE_1/7/AJAIA_12/F3LOCAL(SEL.ETHI0.135.85)//PLATA_13/8/SOOT } \\
\text { D/5/AVO/HUI/7/PLATA_13/8/THKNEE_11 }\end{array}$ \\
\hline G14 & GEN/4/D68.1.93A.1A//RUFF/FGO/3/MTL_5/5/TARRO_1/2*YUAN_1//AJAIA_13/YAZI/3/SOMAT_3/PHAX_1//TILO_1/LOTUS_4/4/CANELO_8//S \\
\hline G15 & $\begin{array}{l}\text { CBC } 509 \text { CHILE/6/ECO/CMH76A.722//BIT/3/ALTAR 84/4/AJAIA_2/5/KJOVE_1/7/AJAIA_12/F3LOCAL(SEL.ETHIO.135.85)//PLATA_13/8/SO0T } \\
\text { OBINIA/3/DUKEM_12/2*RASCON_21 }\end{array}$ \\
\hline G16 & $\begin{array}{l}\text { CBC } 509 \text { CHILE/6/ECO/CMH76A.722//BIT/3/ALTAR 84/4/AJAIA_2/5/KJOVE_1/7/AJAIA_12/F3LOCAL(SEL.ETHI0.135.85)//PLATA_13/8/SO0T } \\
\text { OBINIA/3/DUKEM_12/2*RASCON_21 }\end{array}$ \\
\hline G17 & CBC 514 CHILE/3/AUK/GUIL//GREEN/10/CHEN_1/TEZ/3/GUIL//CIT71/CII/4/SORA/PLATA_12/5/STOT//ALTAR 84/ALD/9/USDA595/3/D67.3/ \\
\hline G18 & GUAYACAN INIA/2*SNITAN/5/CMH85.797//CADO/BOOMER_33/4/ARMENT//SRN_3/NIGRIS_4/3/CANELO_9.1 \\
\hline G19 & PLATA_7/ILBOR_1//SOMAT_3/3/CABECA_2/PATKA_4//BEHRANG/10/1A.1D 5+1-06/2*WB881//1A.1D 5+1-06/3*MOJO/3/SO0TY_9/RASCI \\
\hline G20 & $\begin{array}{l}\text { GUAYACAN INIA/POMA_2//SNITAN/4/D86135/ACO89//PORRON_4/3/SNITAN/5/CAMAYO/GUANAY/4/ARMENT//SRN_3/NIGRIS_4/3/CANELO. } \\
\text { 84/4/AJAIA_2/5/KJOVE_1/7/AJAIA_12/F3LOCAL(SEL.ETHIO.135.85)//PLATA_13/8/SOOTY_9/RASCON_ }\end{array}$ \\
\hline G21 & CAMAYO/2*KUCUK/3/SOOTY_9/RASCON_37//GUAYACAN INIA/5/TARRO_1/2*YUAN_1//AJAIA_13/YAZI/3/SOMAT_3/PHAX_1//TILO_1/LOTUS \\
\hline G22 & AINZEN_1//PLATA_6/GREEN_17/5/TATLER_1/TARRO_1/3/CANELO_8//SORA/2*PLATA_12/4/ARMENT//SRN_3/NIGRIS_4/3/CANELO_9.1 \\
\hline G23 & DACK/KIWI//OSTE/3/CHEN84_1/4/MEXI75/5/NIGRIS_4/6/CANELO_8//SORA/2*PLATA_12/7/SOMAT_4/INTER_8/8/GEDIZ/FGO//GTA/3/SRN_ \\
\hline G24 & SELIM/6/AJAIA_12/F3LOCAL(SEL.ETHIO.135.85)//PLATA_13/3/SOMBRA_20/4/SNITAN/5/SOMAT_4/INTER_8/7/NASR 99/4/BCRIS/BICUM//L \\
\hline G25 & SELIM/3/CF4-JS 21//TECA96/TILO_1/4/SORA/2*PLATA_12//SRN_3/NIGRIS_4 \\
\hline G26 & ARMENT//SRN_3/NIGRIS_4/3/CANELO_9.1/4/TOSKA_26/RASCON_37//SNITAN/5/PLAYERO \\
\hline G27 & WID22241/4/ARMENT//SRN_3/NIGRIS_4/3/CANELO_9.1/5/TARRO_1/2*YUAN_1//AJAIA_13/YAZI/3/SOMAT_4/INTER_8/4/ARMENT//SRN_3/ \\
\hline G28 & ALAMO:DR/4/ARMENT//SRN_3/NIGRIS_4/3/CANELO_9.1/5/PLATA_6/GREEN_17//SNITAN/4/YAZI_1/AKAKI_4//SOMAT_3/3/AUK/GUIL//GREE \\
\hline G29 & E90040/MFOWL_13//LOTAIL_6/3/PROZANA/ARLIN//MUSK_6/9/USDA595/3/D67.3/RABI//CRA/4/ALO/5/HUI/YAV_1/6/ARDENTE/7/HUI/YAV: \\
\hline G30 & $\begin{array}{l}\text { ALTAR } \\
\text { 84/STINT//SILVER_45/3/GUANAY/4/GREEN_14//YAV_10/AUK/10/CMH79.959/CHEN//SOOTY_9/RASCON_37/9/USDA595/3/D67.3/RABI//CR }\end{array}$ \\
\hline G31 & ZENIT/5/SORA/2*PLATA_12//RASCON_37/4/ARMENT//SRN_3/NIGRIS_4/3/CANELO_9.1/6/MINIMUS_4/GRO_2/3/PROZANA/ARLIN//MUSK_6 \\
\hline G32 & SIMETO/3/SORA/2*PLATA_12//SRN_3/NIGRIS_4/5/TOSKA_26/RASCON_37//SNITAN/4/ARMENT//SRN_3/NIGRIS_4/3/CANELO_9.1 \\
\hline G33 & P91.272.3.1/3*MEXI75//2*JUPARE C 2001/5/ARTICO/AJAIA_3//HUALITA/3/FULVOUS_1/MFOWL_13/4/TECA96/TILO_1/6/RISSA/GAN//POHC \\
\hline G34 & P91.272.3.1/3*MEXI75//2*JUPARE C 2001/5/ARTICO/AJAIA_3//HUALITA/3/FULVOUS_1/MFOWL_13/4/TECA96/TILO_1/6/RISSA/GAN//POHC \\
\hline G35 & $\begin{array}{l}\text { ALTAR } \\
\text { 84/STINT//SILVER_45/3/GUANAY/4/GREEN_14//YAV_10/AUK/10/CMH79.959/CHEN//SOOTY_9/RASCON_37/9/USDA595/3/D67.3/RABI//CR }\end{array}$ \\
\hline G36 & T//SRN_3/NIGRIS_4/3/CANELO_9.1/4/STOT//ALTAR 84/ALD/3/PATKA_7/YAZI_1/5/HUALITA \\
\hline
\end{tabular}




\begin{tabular}{|c|c|}
\hline Genotype & Pedigree \\
\hline G37 & ODIN_15/WITNEK_1//ISLOM_1/6/MINIMUS/COMB DUCK_2//CHAM_3/3/FICHE_6/4/MOJO/AIRON/5/SOMAT_3.1 \\
\hline G38 & TRIDENT/3*KUCUK \\
\hline G39 & PLANETA/AMIC//BERGAND/TRILE/3/KNIPA \\
\hline G40 & ATIL/3/KNIPA/TAGUA//PLANETA/TRILE \\
\hline G41 & ATIL/HELLER \#1 CDSS09Y00298S-099Y-043M-27Y-0M-04Y-0B \\
\hline G42 & ATIL/BAIRDS CDSS09Y00386S-099Y-058M-23Y-0M-04Y-0B \\
\hline G43 & ATIL/BAIRDS CDSS09Y00388S-099Y-047M-19Y-0M-04Y-0B \\
\hline G44 & ATIL/3/KNIPA/TAGUA//PLANETA/TRILE \\
\hline G45 & CIRNO C 2008/HELLER \#1 CDSS09Y00771T-099Y-040M-10Y-0M-04Y-0B \\
\hline G46 & CIRNO C 2008/BAIRDS CDSS09Y00795T-099Y-024M-29Y-0M-04Y-0B \\
\hline G47 & CIRNO C 2008/BAIRDS CDSS09Y00449S-099Y-011M-10Y-0M-04Y-0B \\
\hline G48 & CIRNO C 2008/3/KNIPA/TAGUA//PLANETA/TRILE CDSS08B00149T-099Y-056M-16Y-0M-04Y-0B \\
\hline G49 & CIRNO C 2008/3/KNIPA/TAGUA//PLANETA/TRILE CDSS09Y00970T-099Y-063M-11Y-0M-04Y-0B \\
\hline G50 & CIRNO C 2008/3/KNIPA/TAGUA//PLANETA/TRILE CDSS09B00077S-099Y-014M-4Y-3M-06Y-0B \\
\hline G51 & CIRNO C 2008/3/KNIPA/TAGUA//PLANETA/TRILE CDSS10Y00288S-099Y-038M-17Y-1M-06Y-0B \\
\hline G52 & ATIL*2/HELLER \#1 CDSS10Y00291S-099Y-044M-5Y-2M-06Y-0B \\
\hline G53 & ATIL*2/BAIRDS CDSS10Y00491T-099Y-040M-7Y-1M-06Y-0B \\
\hline G54 & ATIL*2/DUNKER CDSS10Y00493T-099Y-035M-9Y-4M-06Y-0B \\
\hline G55 & ATIL*2/3/KNIPA/TAGUA//PLANETA/TRILE CDSS10Y00500T-099Y-028M-1Y-4M-06Y-0B \\
\hline G56 & ATIL*2/3/KNIPA/TAGUA//PLANETA/TRILE CDSS10Y00504T-099Y-037M-5Y-2M-06Y-0B \\
\hline G57 & ATIL*2/3/KNIPA/TAGUA//PLANETA/TRILE CDSS10Y00517T-099Y-055M-13Y-4M-06Y-0B \\
\hline G58 & CIRNO C 2008*2/HELLER \#1 CDSS09B00261T-099Y-046M-7Y-2M-06Y-0B \\
\hline G59 & CIRNO C 2008*2/HELLER \#1 CDSS09B00268T-099Y-050M-3Y-4M-06Y-0B \\
\hline G60 & CIRNO C 2008*2/BAIRDS CDSS09B00347T-099Y-033M-13Y-3M-06Y-0B \\
\hline G61 & CIRNO C 2008*2/BAIRDS CDSS10Y00539T-099Y-025M-29Y-1M-06Y-0B \\
\hline G62 & CIRNO C 2008*2/BAIRDS CDSS10Y00550T-099Y-014M-7Y-3M-06Y-0B \\
\hline G63 & CIRNO C 2008*2/BAIRDS CDSS10Y00550T-099Y-014M-8Y-3M-06Y-0B \\
\hline G64 & CIRNO C 2008*2/BAIRDS CDSS10Y00553T-099Y-068M-8Y-3M-06Y-0B \\
\hline G65 & CIRNO C 2008*2/BAIRDS CDSS10Y00556T-099Y-031M-16Y-2M-06Y-0B \\
\hline G66 & CIRNO C 2008*2/BAIRDS CDSS09B00483D-099Y-032M-2Y-1M-06Y-0B \\
\hline G67 & CIRNO C 2008*2/BAIRDS CDSS09B00490D-099Y-032M-11Y-3M-06Y-0B \\
\hline G68 & CIRNO C 2008*2/BAIRDS CDSS10Y00572T-099Y-030M-13Y-1M-06Y-0B \\
\hline G69 & CIRNO C 2008*2/BAIRDS CDSS10Y00573T-099Y-056M-4Y-4M-06Y-0B \\
\hline G70 & CIRNO C 2008*2/BAIRDS CDSS09B00128S-099Y-057M-1Y-1M-06Y-0B \\
\hline G71 & CIRNO C 2008*2/DUNKER CDSS09B00150S-099Y-023M-4Y-1M-06Y-0B \\
\hline G72 & CIRNO C 2008*2/DUNKER CDSS10Y00017S-099Y-034M-7Y-1M-06Y-0B \\
\hline G73 & CIRNO C 2008*2/DUNKER CMSS08B01003S-099B-099Y-22B-0Y \\
\hline G74 & CIRNO C 2008*2/DUNKER CDSS07Y00746T-099Y-099M-5Y-3M-04Y-0B \\
\hline G75 & CIRNO C 2008*2/DUNKER CDSS07Y00079S-099Y-099M-4Y-2M-04Y-0B \\
\hline G76 & CIRNO C 2008*2/DUNKER CDSS06B00053S-099Y-099M-12Y-2B-04Y-0B \\
\hline G77 & CIRNO C 2008*2/DUNKER CDSS08Y00401S-099Y-028M-9Y-4M-0Y \\
\hline G78 & CIRNO C 2008*2/DUNKER CDSS09Y00029S-099Y-020M-9Y-0M-04Y-0B \\
\hline G79 & CIRNO C 2008^2/3/KNIPA/TAGUA//PLANETA/TRILE CDSS09Y00241S-099Y-022M-10Y-0M-04Y-0B \\
\hline
\end{tabular}




\begin{tabular}{|ll}
\hline Genotype & Pedigree \\
\hline G80 & CIRNO C 2008*2/3/KNIPA/TAGUA//PLANETA/TRILE CDSS09Y00286S-099Y-026M-24Y-0M-04Y-0B \\
\hline G81 & CIRNO C 2008*2/3/KNIPA/TAGUA//PLANETA/TRILE CDSS09Y00762T-099Y-024M-20Y-0M-04Y-0B \\
\hline G83 & CIRNO C 2008*2/3/KNIPA/TAGUA//PLANETA/TRILE CDSS09Y00771T-099Y-040M-3Y-0M-04Y-0B \\
\hline G84 CIRNO C 2008*2/3/KNIPA/TAGUA//PLANETA/TRILE CDSS10Y00498T-099Y-018M-12Y-1M-06Y-0B \\
\hline G85 & CIRNO C 2008*2/3/KNIPA/TAGUA//PLANETA/TRILE CDSS10Y00498T-099Y-018M-18Y-1M-06Y-0B \\
\hline G86 & PLATINUM*2/3/KNIPA/TAGUA//PLANETA/TRILE \\
\hline G87 & Saji \\
\hline G88 & Zahab \\
\hline G89 & SRN-1/KILL//2*FOLTA-1 \\
\hline G90 & Imren \\
\hline
\end{tabular}

\section{Genotyping assays}

In this study, a set of 23 gene-specific primers encoding alleles gliadin, HMWGS, and LMWGS (high and low molecular weight glutenin subunits, respectively), made by Sinaclon Co., Tehran, Iran, were initially tested (Table 2). The polymerase chain reaction was performed using a thermocycler (Techne model TC5000 ) in a volume of $15 \mu \mathrm{l}$ consisted of $2 \mu \mathrm{l}$ template DNA from each sample, one $\mu \mathrm{l}$ of each primer ( 0.5 forward and 0.5 reverse), $4.5 \mu \mathrm{l}$ double distilled water, and $7.5 \mu \mathrm{l}$ master mix. The PCR reaction was carried out as follows: an initial denaturation step at $94^{\circ} \mathrm{C}$ for 5 min, followed by 35 cycles of denaturation at $94^{\circ} \mathrm{C}$ for $30 \mathrm{~s}$, primer annealing at $56^{\circ} \mathrm{C}$ for $30 \mathrm{~s}$ and primer elongation at $72^{\circ} \mathrm{C}$ for $1 \mathrm{~min}$; the final extension at $72^{\circ} \mathrm{C}$ was held for 5 min. The PCR products were electrophoresed on a 1.5\% agarose gel with TBE $1 \mathrm{X}$ buffer, stained with Safe View, and finally photographed under UV light. Of the above 23 markers mentioned, only 12 were polymorphic. Therefore, the experiment was continued based on the 12 markers (Table 2).

Table 2

Locus name and sequences of 12 gene-specific markers related to grain quality used.

\begin{tabular}{|c|c|c|c|c|}
\hline & Marker/gene & Forward Sequences $\left(5^{\prime} \rightarrow 3^{\prime}\right)$ & Backward Sequences $\left(5^{\prime} \rightarrow 3^{\prime}\right)$ & Reference \\
\hline \multirow[t]{2}{*}{$a / \beta$-Gliadin } & gli-AS_3 & TCACCGCTACAACGACCAAACCATGTTT & GCAACCATTTCTGCCACAACTACCAT & Kawaura et al. (2006) \\
\hline & gli-AS_4 & CCTAGGCCTATGGGTTCTGCTGAGA & GCAACCACAGTATCCGCAACCAC & Kawaura et al. (2006) \\
\hline \multirow[t]{8}{*}{ LMW-GS } & glu-AS_2 & GGCACAGGGTACCTTTTTGCATC & ATACAAGGGCACATTGACACGGC & Kawaura et al. (2006) \\
\hline & glu-A1 & CGAGACAATATGAGCAGCAAG & CTGCCATGGAGAAGTTGGA & Li et al. (2008) \\
\hline & glu3A.1 & GCCGTTGCGCAAATTTCACAG & AACAGATGGATGAATAACTGGTAT & Long et al. (2005) \\
\hline & glu3A.2 & AGTGCCATTGCGCAGATGAAT & AACGGATGGTTGAACAATAGA & Long et al. (2005) \\
\hline & glu3A.3 & ATGGAGACTAGCTGCATCC & CTGCAAAAAGGTACCCTTTT & \\
\hline & glu-AЗас & AAACAGAATTATTAAAGCCGG & GTGGCTGTTGTGAAAACGA & Wang et al. (2010) \\
\hline & glu-A3f & AAACAGAATTATTAAAGCCGG & GCTGCTGCTGCTGTGTAAA & Wang et al. (2010) \\
\hline & glu-A3g & AAACAGAATTATTAAAGCCGG & AAACAACGGTGATCCAACTAA & Wang et al. (2010) \\
\hline \multirow[t]{2}{*}{ HMW-GS } & $A \times 2$ * & ATGACTAAGCGGTTGGTTCTT & АССTTGCTCССCTTGTCTTT & Ma et al. (2003) \\
\hline & ZSBy9aF1/R3 & TTCTCTGCATCAGTCAGGA & AGAGAAGCTGTGTAATGCC & Lei et al. (2006) \\
\hline
\end{tabular}

\section{Data analysis}

First, bands formed on the gel were scored as absent (0) and present (1), compiling the data as a binary matrix. To compare the banding patterns of primers, some genetic parameters were calculated by using PowerMarker 3.25 software (He et al. 2020). The Polymorphic Information Content (PIC) of each locus was calculated as $P I C=1-\sum_{i}^{n} p_{i}^{2}$, where $p_{i}$ is the frequency of the ith allele. The Resolving power (Rp) of each locus was calculated as $R p=\Sigma 1$ - $(2 \times|0.5-\mathrm{pi}|)$. The heterozygosity $(\mathrm{He})$ value was computed according to Nei's formula as $H e=1-\sum_{i=1}^{n} p_{i}^{2}$. The Shannon's Information index was determined as $I=-\Sigma p i \times \operatorname{In}$ pi. The genetic variability indices, including total amplified bands (TAB), the number of polymorphic bands (NPB), percentage of polymorphic bands (PPB), the effective number of alleles (Ne), Nei's gene diversity (h), diversity among populations (Gst), and the estimate of gene flow (Nm) were estimated using POPGENE version 1.32 (Negisho et al. 2021). The distribution of genetic variation within and among populations (AMOVA) and principal coordinate analysis (PCOA) was carried out using the GenAlex 6.5 software (Peakall and Smouse 2012). The model-based STRUCTURE version 2.3.4 was used to recognize subpopulations of genetically similar individuals. The optimal number of subpopulations was determined by using Structure Harvester software (Earl and 
vonHoldt 2012) according to the $\Delta K$ approach proposed by Evanno et al. (2005). Cluster analysis was performed using MEGA 6.0 software. First, the Jaccard's dissimilarity distance matrix was calculated using DARWIN software version 6.0 (Shaygan et al. 2021). Afterward, the cluster dendrogram was obtained using the neighbor-joining method based on the distance matrix.

\section{Results}

Of the 23 initial FMs tested on 90 durum genotypes, only 12 (52.2\%) were polymorphic. These 12 primers created a total of 52 polymorphic bands. On average, 4.33 bands were amplified per primer of which, four primers had only two bands, whereas glu3A.1 and glu-A3ac produced seven bands (Table 3). The mean number of effective alleles (Ne) was 1.56 per locus. Markers gli-AS_4 and glu-A1 with 1.98 and 1.01 alleles showed the highest and lowest Ne, respectively. The polymorphism information content (PIC) values varied from 0.011 (by glu-A1) to 0.287 (by $A x 2$ *), with an average of 0.139 . The highest and lowest values of marker index (MI) were observed for primer $A \times 2 *(1.72)$ and primer glu-A1 (0.011), respectively, with an average of 0.68 (Table 3 ). Furthermore, the mean values for resolving power (Rp) was 4.51 and ranged from 2.38 to 8.97 for primers gli-AS_3 and $A x 2$ *, respectively (Table 3 ).

Table 3

Discriminating power statistics and the amplification results of 12 gene-specific markers related to grain quality used in the study.

\begin{tabular}{|c|c|c|c|c|c|c|c|c|}
\hline & Marker/Locus & TAB & NPB & РPB\% & $\mathrm{Ne}$ & PIC & MI & Rp \\
\hline \multirow[t]{2}{*}{$\alpha / \beta$-Gliadin } & gli-AS_3 & 2 & 1 & 50 & 1.81 & 0.153 & 0.306 & 2.38 \\
\hline & gli-AS_4 & 6 & 5 & 83.3 & 1.98 & 0.045 & 0.271 & 5.88 \\
\hline \multirow[t]{8}{*}{ LMW-GS } & glu-AS_2 & 5 & 4 & 80 & 1.74 & 0.261 & 1.306 & 4.20 \\
\hline & glu-A1 & 2 & 1 & 50 & 1.01 & 0.011 & 0.011 & 3.97 \\
\hline & glu3A.1 & 7 & 6 & 85.7 & 1.60 & 0.216 & 1.516 & 3.80 \\
\hline & glu3A.2 & 6 & 6 & 100 & 1.60 & 0.104 & 0.625 & 3.16 \\
\hline & glu3A.3 & 3 & 1 & 50 & 1.72 & 0.060 & 0.180 & 4.20 \\
\hline & glu-A3ac & 7 & 7 & 100 & 1.83 & 0.150 & 1.050 & 5.55 \\
\hline & glu-A3f & 4 & 3 & 75 & 1.78 & 0.225 & 0.900 & 4.44 \\
\hline & glu-A3g & 2 & 1 & 50 & 1.14 & 0.123 & 0.247 & 3.71 \\
\hline \multirow[t]{3}{*}{ LMW-GS } & $A \times 2$ * & 6 & 6 & 100 & 1.50 & 0.287 & 1.720 & 8.97 \\
\hline & ZSBy9aF1/R3 & 2 & 2 & 100 & 1.04 & 0.043 & 0.086 & 3.91 \\
\hline & Mean & 4.33 & 3.58 & 77.00 & 1.56 & 0.139 & 0.680 & 4.51 \\
\hline
\end{tabular}

The results of the population structure analysis have been shown in Figs. 1 and 2. First, to detect the optimal number of subpopulations that best fit the data, the likelihood values of partitioning $(\Delta K)$ were plotted across multiple values of $K$ (Fig. 1), assuming that the loci are independent in Hardy-Weinberg equilibrium and $K$ is the number of populations. As shown in Fig. 1, the maximum likelihood value was obtained when the initial population was divided into four subpopulations. Accordingly, the durum wheat collection was classified into four subpopulations, containing 30, 19, 33, and 8 members, respectively (Fig. 2). The summary of the genetic diversity parameters of the four detected populations has been shown in Table 4 . The percentage of polymorphic loci were $42.31,44.23,42.31$, and 75.00 for subpopulations 1 to 4 , respectively. The number of different alleles ranged from 1.13 for subpopulation 1 to 1.69 for subpopulation 4. Similarly, subpopulations 1 and 4 with 1.18 and 1.38 had the lowest and the highest number of effective alleles, respectively. Also, the Shannon's index were $0.18,0.21,0.19$, and 0.37 , for subpopulations 1 to 4 , respectively. Furthermore, the Nei's gene diversity values were $0.11,0.14,0.12$, and 0.24 , respectively (Table 4). These results revealed that subpopulation 4 genotypes had the highest genetic variation than others while subpopulation 1 had the lowest.

Table 4

Summary of genic variation statistics estimated using gene-specific primers related to grain quality for the four subpopulations studied durum wheat

\begin{tabular}{|c|c|c|c|c|c|c|}
\hline Sub pop No. & Size & PPL\% & $\mathrm{Na}$ & $\mathrm{Ne}$ & I & $\mathrm{h}$ \\
\hline 1 & 30 & 42.31 & 1.13 & 1.18 & 0.18 & 0.11 \\
\hline 2 & 19 & 44.23 & 1.23 & 1.22 & 0.21 & 0.14 \\
\hline 3 & 33 & 42.31 & 1.21 & 1.20 & 0.19 & 0.12 \\
\hline 4 & 8 & 75.00 & 1.69 & 1.38 & 0.37 & 0.24 \\
\hline
\end{tabular}

The allele distribution statistics across the 4 populations have been presented in Fig. 3. Population 4 showed the highest numbers of different bands (49) whereas population 1 had the lowest (37). There were 2 and 7 bands unique to populations 2 and 4 , respectively. Also, no bands were found at less than or 
equal to $25 \%$ of the population. The number of less common bands presented at less than or equal to $50 \%$ of the populations was reported in subpopulations 2,3 , and 4 . Likewise, the mean diversity ranged from 0.112 (population 1 ) to 0.238 (population 4 ).

The analysis of molecular variance (AMOVA) showed that the variation between the populations was $18 \%$ of the total variation while $82 \%$ of the variations were among individuals within the population, indicating that most amplified fragments were informative for separating the genotypes. In addition, the diversity among populations and gene flow were 0.14 and 3.03 , respectively (Table 5).

Table 5

Analysis of molecular variance (AMOVA) based on Gene-specific markers related to grain quality for four populations of durum wheat

\begin{tabular}{|lllllll|}
\hline Source & df & SS & MS & Est. Var. & Variation (\%) & Gst \\
\hline Among Pops & 3 & 61.441 & 20.480 & 0.796 & $18 \%$ & \\
\hline Within Pops & 86 & 309.259 & 3.596 & 3.596 & $82 \%$ & 0.14 \\
\hline Total & 89 & 370.700 & & 4.392 & $100 \%$ & 3.03
\end{tabular}

$d f$ degree of freedom, $S S$ sum of squares, $M S$ means of squares, Est. Var estimated variance components, Gst diversity among populations, Nm estimate of gene flow.

Calculation of the Jaccard distance coefficient revealed that genetic dissimilarities ranged from 0.031 between G62 and G65 to 0.725 between G36 and G51

(Data not shown). These results showed that the primers used in the study had an appropriate potential for calculating genetic distances and detecting relationships among durum wheat genotypes.

Cluster analysis based on the neighbor-joining method grouped the 90 individuals into four main clusters (Fig. 4). According to the subpopulations, the clustering pattern was different from that detected by structure classification results.

The results of the Principal coordinates analysis revealed that genotype G51 had a significant load on the first coordinate. Besides, due to their relatively large distance from other genotypes, G51, G70 had the highest degree of dissimilarity compared to different genotypes (Fig. 5).

\section{Discussion}

Genetic diversity stems from the natural selection of wild ancestors and mediation through farmers and breeders. The study of genetic diversity is essential in understanding the structure of germplasm. So far, genetic diversity analysis in crops has been applied for breeding programs related to the marker-trait association, marker-assisted selection, creation of artificial variation to find specific hybrids, and crop germplasm conservation (Negisho et al. 2021). In the past decades, different molecular tools such as neutral and functional DNA markers were introduced to plant breeding programs. Compared with neutral DNA markers, FMs have the advantage of being entirely associated with target genes. Therefore, FMs have been preferred in biodiversity studies (van Tienderen et al. 2002; Wu et al. 2020).

In this study, polymorphisms derived from FMs related to grain quality proteins were used to evaluate the genetic diversity of a collection of 90 durum wheat genotypes for future selective breeding programs. The results showed a relatively high level of molecular variability among the studied genotypes. Compared to neutral markers, the markers used in this study have been occasionally used in genetic diversity assays because gene-specific primers are often used in marker-assisted selection programs (Liu et al. 2012). Therefore, this is the first-of-its-kind report which shows the applicability of FMs, associated with wheat grain quality proteins, in assessing the genetic diversity of durum wheat. Significant polymorphisms and the formation of more than one band were among the practical factors in obtaining acceptable results. Some other kinds of FMs, such as CAAT box-derived polymorphism primers, have been used successfully to evaluate the genetic diversity of durum wheat (Shaygan et al. 2021; Etminan et al. 2019; Khodaee et al. 2021; Ghobadi et al. 2021).

According to our results, FMs had an acceptable percentage of polymorphic bands. Also, Marker information parameters showed the differentiation power of these primers and thus the appropriate efficiency of this type of DNA marker to investigate the genetic diversity in the germplasm of durum wheat. Of the primers used, four primers had PIC values above 0.20 , indicating that these primers were informative in determining polymorphism. AMOVA results revealed that there was a higher percentage of genetic variation within durum populations than among populations. This result is also confirmed by the Gst value (diversity among populations). Zang et al. (2018) proposed that Gst is an important parameter to measure whether genetic differentiation exists among populations. When the Gst value falls between 0.05 and 0.15 , the genetic differentiation is considered as the medium. Therefore the identified subpopulations were estimated to have the medium value of genetic differentiation. The $\mathrm{Nm}$ index, the number of migrants per generation, is an estimation of the gene flow. The distribution of genetic diversity between and within populations is a consequence of the amount of gene flow between them. Gene flow rate, in turn, is affected by the number of seeds or pollen that move between populations (Etminan et al. 2018). Nm values higher than 1 indicate that a weak possibility of genetic drift inhibits differentiation among populations whereas Nms less than 1 specify that local populations tend to differentiate. Hence, the higher Nm the less genetic differentiation among populations (Chen et al. 2020). Accordingly, in our study, the existence of large gene flow (Nm $=3.03$ ) among populations decreased the degree of genetic differentiation among populations.

The Nei genetic diversity index and the Shannon Index are known as the most genetic diversity parameters to show diversity and differentiation between and within populations (Carvalho et al. 2010). The higher values of these indices denote the greater the genetic diversity (Que et al. 2014). In the current study, the level of variability between $\mathrm{h}$ and I indices revealed a high level of genetic diversity among subpopulations 2 and 4 . The former was rich in a/ $\beta$-Gliadin alleles while the latter showed a high percentage of bands associated with HMW-GS (data not shown). These results indicated that these populations of durum wheat may be a good source of grain quality-related protein subunits that can be used for a variety of purposes including breeding programs related to quality improvement especially in crosses with elite durum wheat germplasm. 
As it can be seen, the clustering pattern (Fig. 4) was not consistent with that obtained from the population structure algorithm (Fig. 2). STRUCTURE identifies subsets by detecting allele frequency differences within the data and assigns individuals to those sub-populations based on analysis of likelihoods (PorrasHurtado et al. 2013) while cluster analysis subdivides cases into clusters according to a specific measure of similarity and arranges cases in a hierarchy. Therefore, the observed results may be due to differences in the algorithm of the two methods. For example, in cluster analysis, a relatively large genetic distance between genotype G51 and other genotypes left this genotype in a single group while such a thing was not observed in grouping by STRUCTURE analysis (Figs. 2 and 4). This result is also supported by PCoA analysis (Fig. 5)

Breeding targets will have an advantage when the focus is on the cross of distant genotypes, or to increase diversity and identify new genes to further improve wheat. Hence, the classification and characterization of wheat germplasm is a prerequisite stage in the selection and improvement of wheat. The results of this study could be useful to select parents to be crossed for obtaining new appropriate populations intended for transgressive segregation of some important agronomic characters in the descendant populations. Our results confirmed a high level of genetic diversity in the studied genotypes. In addition, the results revealed that the FMs were reproducible, efficient, and powerful to assess genetic diversity among durum wheat genotypes.

\section{Abbreviations}

AMOVA Analysis of molecular variance

FM Functional marker

HMWGs High molecular weight glutenin subunits

IShannon's Information Index

LMWGs Low molecular weight glutenin subunits

MIMarker index

Ne Number of effective alleles

$\mathrm{Nm}$ The estimate of gene flow

NPB The number of polymorphic bands

$P C O A$ Principal coordinate analysis

PIC Polymorphism information content

$P P B$ Percentage of polymorphic bands

Rp Resolving power

TAB Total amplified bands

UPGMA Unweighted pair group method with arithmetic mean

\section{Declarations}

Acknowledgments The authors thank the Sararud Dryland Agricultural Research Institute of Kermanshah for its sincere cooperation in providing the genotypes.

\section{Author contributions}

Conceptualization: ZMKh, RA, AMM, MK, AE; Data curation: RA, AMM, MK, AE; Formal analysis: ZMKh, RA; Investigation: ZMKh, RA, AMM, MK, AE; Methodology: RA, AMM, MK, AE; Validation: RA, AMM, MK, AE; Writing original draft: ZMKh, Review, and editing: RA, AE

Funding Not applicable.

Data availability Data related to the results obtained in the present study are available from the corresponding author by request.

Ethics approval Not applicable

Conflict of interest The authors of this article have no conflicts of interest.

Consent for publication All authors have given their consent for publication.

\section{References}


1. Alemu A, Feyissa T, Letta T, Abeyo B (2020) Genetic diversity and population structure analysis based on the high-density SNP markers in Ethiopian durum wheat (Triticum turgidum ssp. durum). BMC Genet 21(1):18. https://doi.org/10.1186/s12863-020-0825-x

2. Aslan-parviz M, Omidi M, Rashidi V, Etminan A, Ahmadzadeh A (2020) Evaluation of genetic diversity of durum wheat (Triticum durum desf.) genotypes using inter-simple sequence repeat (ISSR) and caat box-derived polymorphism (CBDP) markers. Genetika 52(3):895-909. https://doi.org/10.2298/GENSR2003895A

3. Carvalho MA, Quesenberry KH, Gallo M (2010) Comparative assessment of variation in the USA Arachis pintoi (Krap. and Greg.) germplasm collection using RAPD profiling and tissue culture regeneration ability. Plant Syst Evol 288(3):245-251. https://doi.org/10.1007/s00606-010-0335-9

4. Chegdali Y, Ouabbou H, Essamadi A, Cervantes F, Ibba Ml, Guzmán C (2020) Assessment of the glutenin subunits diversity in a durum wheat (T. turgidum ssp. durum) collection from Morocco. Agron J 10(7):957

5. Chen C, Chu Y, Ding C, Su X, Huang Q (2020) Genetic diversity and population structure of black cottonwood (Populus deltoides) revealed using simple sequence repeat markers. BMC Genet 21(1):2. https://doi.org/10.1186/s12863-019-0805-1

6. Earl DA, vonHoldt BM (2012) STRUCTURE HARVESTER: a website and program for visualizing STRUCTURE output and implementing the Evanno method. Conserv Genet Resour 4(2):359-361. https://doi.org/10.1007/s12686-011-9548-7

7. El Haddad N, Kabbaj H, Zaïm M, El Hassouni K, Tidiane Sall A, Azouz M, Ortiz R, Baum M, Amri A, Gamba F, Bassi FM (2021) Crop wild relatives in durum wheat breeding: Drift or thrift? Crop Sci 61(1):37-54. https://doi.org/10.1002/csc2.20223

8. Etminan A, Pour-Aboughadareh A, Mehrabi AA, Shooshtari L, Ahmadi-Rad A, Moradkhani H (2019) Molecular characterization of the wild relatives of wheat using CAAT-box derived polymorphism. Plant Biosyst 153(3):398-405. https://doi.org/10.1080/11263504.2018.1492993

9. Etminan A, Pour-Aboughadareh A, Mohammadi R, Noori A, Ahmadi-Rad A (2018) Applicability of CAAT Box-derived Polymorphism (CBDP) markers for analysis of genetic diversity in durum wheat. Cereal Res Commun 46(1):1-9. https://doi.org/10.1556/0806.45.2017.054

10. Evanno G, Regnaut S, Goudet J (2005) Detecting the number of clusters of individuals using the software STRUCTURE: a simulation study. Mol Ecol 14(8):2611-2620. https://doi.org/10.1111/j.1365-294X.2005.02553.x

11. Fattah YM, Tayib NN (2020) Assessment of genetic diversity and population structure of some soft and hard wheat varieties based on SSR marker. Sci j Univ Zakho 8(3):80-87

12. Fayaz F, Aghaee Sarbarzeh M, Talebi R, Azadi A (2019) Genetic diversity and molecular characterization of Iranian durum wheat landraces (Triticum turgidum durum (Desf.) Husn.) using DArT markers. Biochem Genet 57(1):98-116. https://doi.org/10.1007/s10528-018-9877-2

13. Ghobadi G, Etminan A, Mehrabi AM, Shooshtari L (2021) Molecular diversity analysis in hexaploid wheat (Triticum aestivum L.) and two Aegilops species (Aegilops crassa and Aegilops cylindrica) using CBDP and SCoT markers. J Genet Eng Biotechnol 19(1):56. https://doi.org/10.1186/s43141-021-00157-8

14. He Z, Rasheed A, Xia X, Ma W (2020) Molecular marker development and application for improving qualities in bread wheat. In: Igrejas G, Ikeda TM, Guzmán C (eds) Wheat Quality For Improving Processing And Human Health. Springer International Publishing, Cham, pp 323-345. https://doi.org/10.1007/978-3-030-34163-3_14

15. Hsia CC, Anderson OD (2001) Isolation and characterization of wheat $\omega$-gliadin genes. Theor Appl Genet 103(1):37-44. https://doi.org/10.1007/s00122001-0552-2

16. Irani P (2000) Pasta quality traits of some durum wheat varieties. J Agric Sci Technol 2(2):143-148

17. Kage U, Kumar A, Dhokane D, Karre S, Kushalappa AC (2016) Functional molecular markers for crop improvement. Crit Rev Biotechnol 36(5):917-930. https://doi.org/10.3109/07388551.2015.1062743

18. Kawaura K, Mochida K, Ogihara Y (2006) Expression profile of two storage-protein gene families in hexaploid wheat revealed by large-scale analysis of expressed sequence tags. Plant Physiol 139:1870-1880. https://doi.org/10.1104/pp.105.070722

19. Khodaee L, Azizinezhad R, Etminan AR, Khosroshahi M (2021) Assessment of genetic diversity among Iranian Aegilops triuncialis accessions using ISSR, SCoT, and CBDP markers. J Genet Eng Biotechnol 19(1):5. https://doi.org/10.1186/s43141-020-00107-w

20. Kumar S, Kumar M, Mir RR, Kumar R, Kumar S (2021) Advances in molecular markers and their use in genetic improvement of wheat. In: Wani SH, Mohan A, Singh GP (eds) Physiological, Molecular, and Genetic Perspectives of Wheat Improvement. Springer, Cham. https://doi.org/10.1007/978-3-030-595777_8

21. Lei ZS, Gale KR, He ZH, Gianibelli C, Larroque O, Xia XC, Butow BJ, Ma W (2006) Y-type gene-specific markers for enhanced discrimination of highmolecular-weight glutenin alleles at the Glu-B1 locus in hexaploid wheat. J Cereal Sci 43(1):94-101. https://doi.org/10.1016/j.jcs.2005.08.003

22. Li W, Zeng X, Li S, Chen F, Gao J (2020) Development and application of two novel functional molecular markers of BADH2 in rice. Electron J Biotechnol 46:1-7. https://doi.org/10.1016/j.ejbt.2020.04.004

23. Li X, Wang A, Xiao Y, Yan Y, He Z, Appels R, Ma W, Hsam SLK, Zeller FJ (2008) Cloning and characterization of a novel low molecular weight glutenin subunit gene at the Glu-A3 locus from wild emmer wheat (Triticum turgidum L. var. dicoccoides). Euphytica 159(1):181-190. https://doi.org/10.1007/s10681-007-9471-x

24. Liu Y, He Z, Appels R, Xia X (2012) Functional markers in wheat: current status and future prospects. Theor Appl Genet 125(1):1-10. https://doi.org/10.1007/s00122-012-1829-3

25. Long H, Wei Y-M, Yan Z-H, Baum B, Nevo E, Zheng Y-L (2005) Classification of wheat low-molecular-weight glutenin subunit genes and its chromosome assignment by developing LMW-GS group-specific primers. Theor Appl Genet 111(7):1251-1259. https://doi.org/10.1007/s00122-005-0024-1

26. Ma W, Zhang W, Gale KR (2003) Multiplex-PCR typing of high molecular weight glutenin alleles in wheat. Euphytica 134(1):51-60. https://doi.org/10.1023/A:1026191918704 
27. Magallanes-López AM, Ammar K, Morales-Dorantes A, González-Santoyo H, Crossa J, Guzmán C (2017) Grain quality traits of commercial durum wheat varieties and their relationships with drought stress and glutenins composition. J Cereal Sci 75:1-9. https://doi.org/10.1016/j.jcs.2017.03.005

28. Murray MG, Thompson WF (1980) Rapid isolation of high molecular weight plant DNA. Nucleic acids research 8(19):4321-4325. https://doi.org/10.1093/nar/8.19.4321

29. Negisho K, Shibru S, Pillen K, Ordon F, Wehner G (2021) Genetic diversity of Ethiopian durum wheat landraces. Plos one 16(2):e0247016

30. Peakall R, Smouse PE (2012) GenAlEx 6.5: genetic analysis in Excel. Population genetic software for teaching and research-an update. Bioinformatics 28(19):2537-2539. https://doi.org/10.1093/bioinformatics/bts460

31. Porras-Hurtado L, Ruiz Y, Santos C, Phillips C, Carracedo A, Lareu MV (2013) An overview of STRUCTURE: applications, parameter settings, and supporting software. Front Genet 4:98-98. https://doi.org/10.3389/fgene.2013.00098

32. Que Y, Pan Y, Lu Y, Yang C, Yang Y, Huang N, Xu L (2014) Genetic analysis of diversity within a chinese local sugarcane germplasm based on start codon targeted polymorphism. Biomed Res Int 2014:468375. https://doi.org/10.1155/2014/468375

33. Regina A, Guzmán C (2020) Starch and starch-associated proteins: Impacts on wheat grain quality. In: Igrejas G, Ikeda T, Guzmán C (eds) Wheat Quality For Improving Processing And Human Health. Springer, Cham. https://doi.org/10.1007/978-3-030-34163-3_3

34. Shaygan N, Etminan A, Majidi Hervan I, Azizinezhad R, Mohammadi R (2021) The study of genetic diversity in a minicore collection of durum wheat genotypes using agro-morphological traits and molecular markers. Cereal Res Commun 49(1):141-147. https://doi.org/10.1007/s42976-020-00073-6

35. van Tienderen PH, de Haan AA, van der Linden CG, Vosman B (2002) Biodiversity assessment using markers for ecologically important traits. Trends Ecol Evol 17(12):577-582. https://doi.org/10.1016/S0169-5347(02)02624-1

36. Wang L, Li G, Peña RJ, Xia X, He Z (2010) Development of STS markers and establishment of multiplex PCR for Glu-A3 alleles in common wheat (Triticum aestivum L.). J Cereal Sci 51(3):305-312. https://doi.org/10.1016/j.jcs.2010.01.005

37. Wu Y, Li M, He Z, Dreisigacker S, Wen W, Jin H, Zhai S, Li F, Gao F, Liu J, Wang R, Zhang P, Wan Y, Cao S, Xia X (2020) Development and validation of highthroughput and low-cost STARP assays for genes underpinning economically important traits in wheat. Theor Appl Genet 133(8):2431-2450. https://doi.org/10.1007/s00122-020-03609-w

38. Xynias IN, Mylonas I, Korpetis EG, Ninou E, Tsaballa A, Avdikos ID, Mavromatis AG (2020) Durum wheat breeding in the mediterranean region: current status and future prospects. Agron J 10(3):432

39. Zang R, Zhao Y, Guo K, Hong K, Xi H, Wen C (2018) The population genetic variation analysis of bitter gourd wilt caused by Fusarium oxysporum f. sp. momordicae in China by inter simple sequence repeats (ISSR) molecular marker. bioRxiv:424077. https://doi.org/10.1101/424077

\section{Figures}

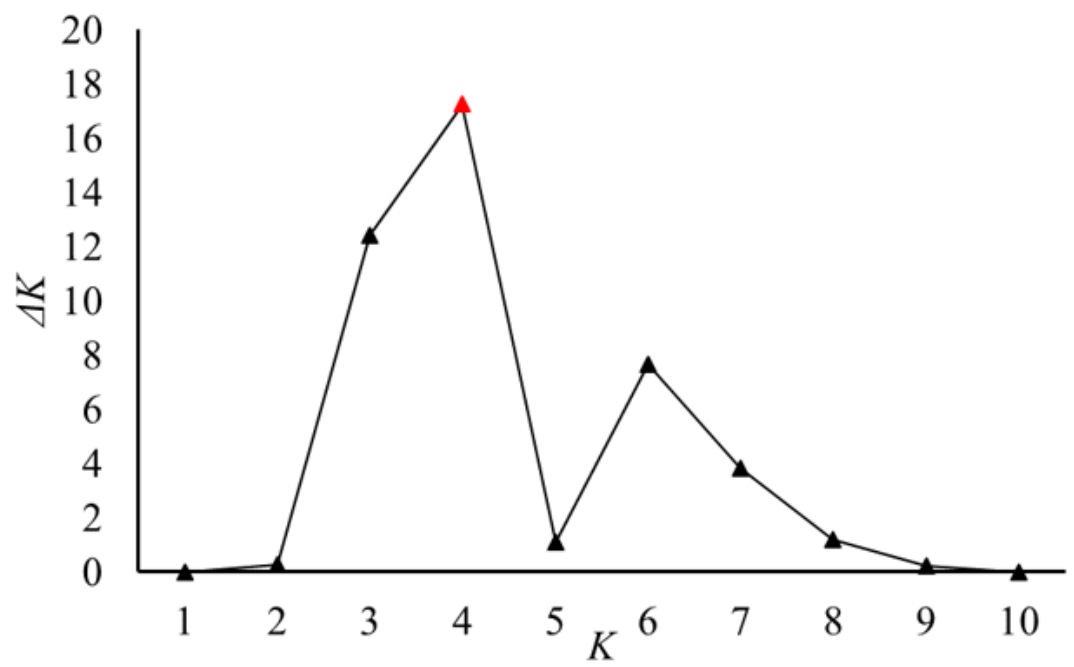

Figure 1

Detection of the optimal number of $\mathrm{K}$ subpopulations of 90 durum wheat genotypes based on data obtained by 12 gene-specific primers related to grain quality traits (Evanno et al. 2005). 


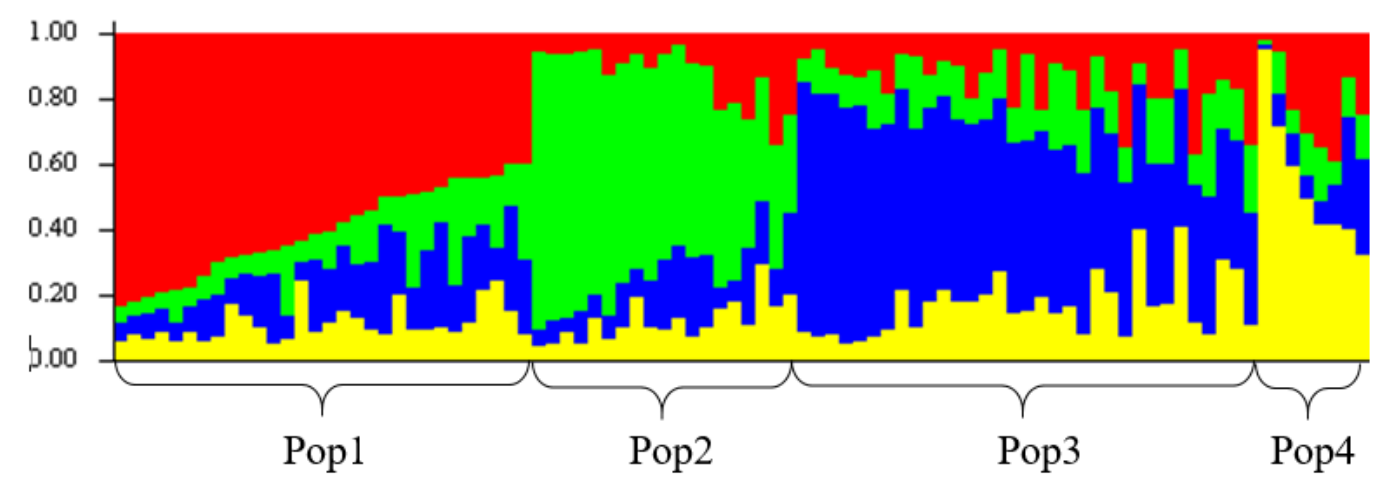

\section{Figure 2}

Bayesian model-based population structure based on data obtained by 12 gene-specific markers related to grain quality traits in 90 durum wheat genotypes.

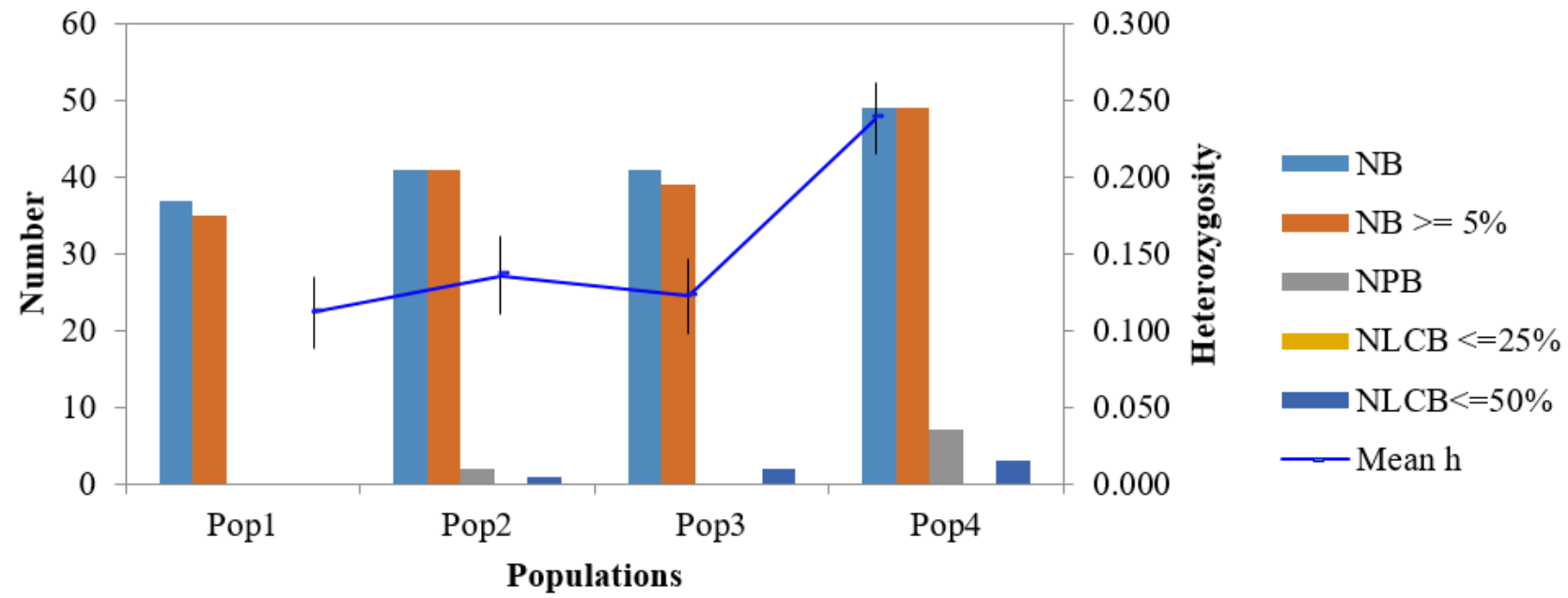

\section{Figure 3}

Allele distribution statistics across populations of 90 durum wheat genotypes NB No. of different bands, NB >= $5 \%$ No. of different bands with a frequency >= $5 \%$, NPB No. of bands unique to a single population, NLCB $<=25 \%$ No. of locally common bands (Freq. $>=5 \%$ ) found in $25 \%$ or fewer populations, NLCB $<=50 \%$ No. of locally common bands (Freq. $>=5 \%)$ found in $50 \%$ or fewer populations $h$ Diversity $\left(1-\left(p^{\wedge} 2+q^{\wedge} 2\right)\right)$ 


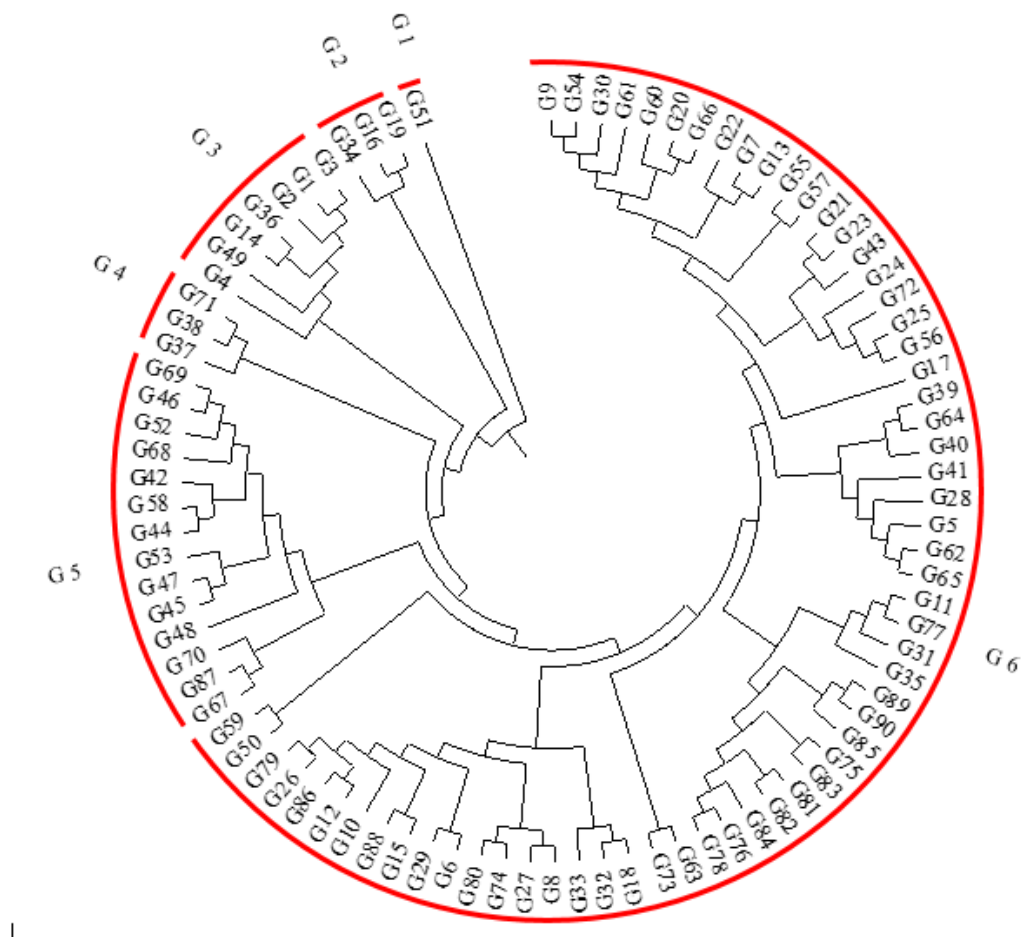

Figure 4

UPGMA phylogenetic dendrogram according to Jaccard's distance coefficient based on data obtained by 12 gene-specific markers related to grain quality traits on 90 durum wheat genotypes.

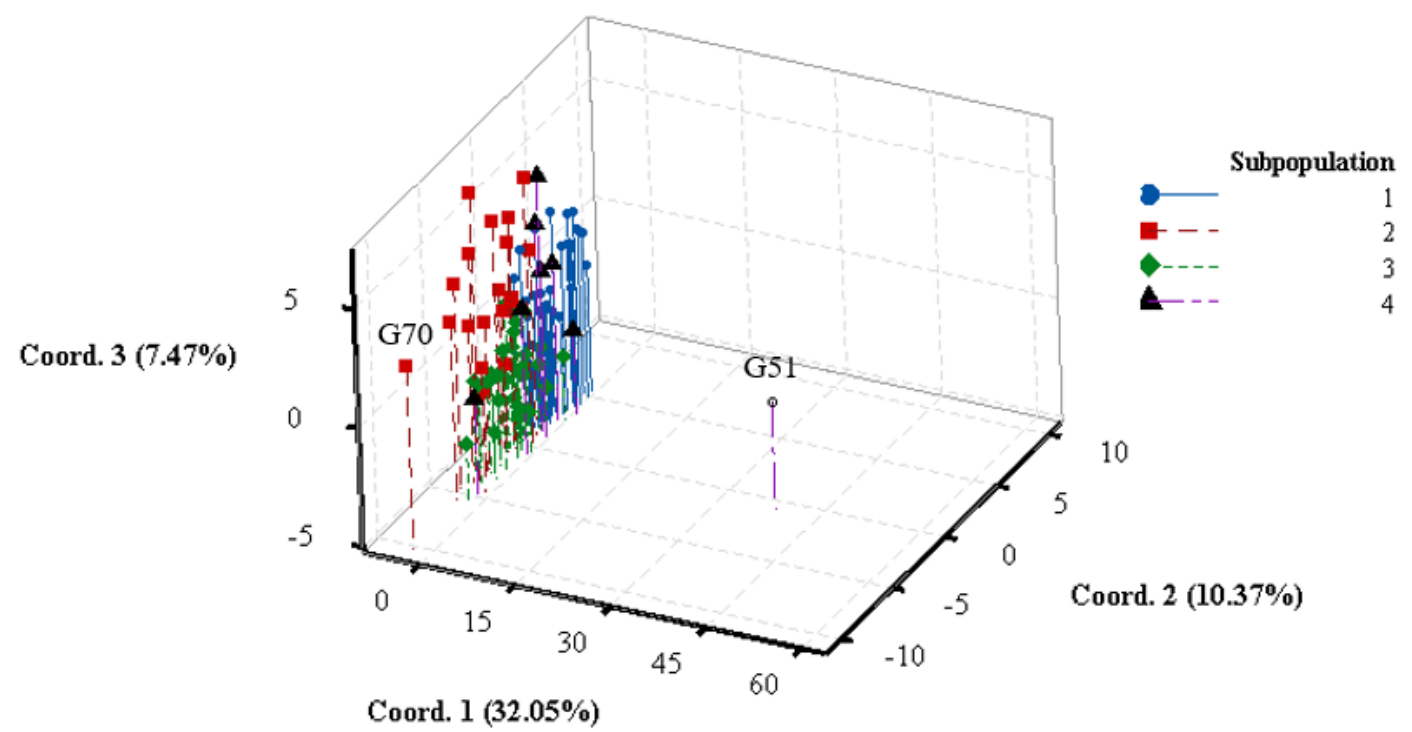

\section{Figure 5}

principal coordinate analysis based on data obtained by 12 gene-specific markers related to grain quality traits on 90 durum wheat genotypes. 